\title{
MATHIAS EICHHORN
}

\section{Erwählung - Bildung - Demokratie}

\author{
Das Gemeinwohlverständnis in der reformierten Tradition*
}

\section{Exposition}

„Sag ihm, daß ich, der Mayor und Aldermänner, / In trift'ger Absicht, Sachen von Gewicht / Betreffend wen'ger nichts als aller Wohl / Hier sind um ein Gespräch mit seiner Gnaden."

Es sind diese Worte, die Shakespeare dem heuchlerischen Buckingham in den Mund legt, als der vor den Augen und Ohren der Vertreter des Volks und in deren Namen um Audienz beim Herzog von Gloster, dem späteren Richard III, ersucht. Die dann nachfolgende Szene läßt Shakespeare zwischen Buckingham und Gloster abgesprochen sein. Es soll nämlich so erscheinen, als müsse einem vor der Verantwortung zurückschreckenden Herzog die Krone aufgenötigt werden. Annähernd so überzeugend hat in unserer Zeit diese Rolle nur Helmut Schmidt zu spielen versucht, als er den ihm an Charisma weit überlegenen Willy Brandt als Bundeskanzler abzulösen unternahm. Freilich hat Schmidt sich seinerzeit, im Jahre 1974, nicht wie Gloster im Gebet versunken und von zwei Bischöfen flankiert dem SPD-Parteitag gezeigt. Daß Richard bei Shakespeare so auftritt, hat mit dem im Mittelalter vorherrschenden Verständnis dessen zu tun, was der Dichter the general good nennt. Folgt man nämlich Michael Walzer, dann entsprach unserer Erwartung heute, daß der Staat ein Sozialstaat sei in dem Sinne, daß er zumindest die Aufgabe der sozialen Grundversorgung zu übernehmen habe, im mittelalterlichen Europa die Erwartung an die Regierenden, daß sie die anstaltsmäßige Vermittlung der ewigen Seligkeit sichern sollten. ${ }^{2}$ Freilich, Shakespeare schreibt nicht mehr im Mittelalter, aber die kollektive Erinnerung an die Zeit, als man noch wie selbstverständlich nach Canterbury pilgerte, war wachgeblieben. Die Anstalt nun, die einst zur Vermittlung des Heils alleine als befähigt angesehen wurde, war die Kirche, und sie zu schützen und mit Stiftungen zu bedenken, legitimierte die politische Macht. Es mutet darum sogar unverhofft

\footnotetext{
* Viele Anregungen für dieses Thema verdanke ich der Predigttätigkeit von Pfr. Milton Aylor und der Lehrtätigkeit von Prof. Dieter Georgi im Rahmen der Erwachsenenbildung in der DeutschReformierten Gemeinde in Frankfurt.

1 Shakespeare, Richard III, 3,7.

2 Vgl. Walzer, 1998, S. $138 \mathrm{f}$.
} 
evangelisch an, wenn Shakespeare den Gloster auf den Vorwurf hin, er habe in Edward, dem dem Hause Lancaster entstammenden Prinzen von Wales, einen Ausbund an Tugend hingemordet, erwidern läßt: „So taugt er, bei des Himmels Herrn zu wohnen. / [...] Er danke mir, der ihm dahin verholfen: / Er taugte für den Ort, nicht für die Erde. ${ }^{63}$ Doch Richard, der sich ja vor allem Volk noch als einer zeigt, der ganz der alten Welt verpflichtet ist, konterkariert hier nicht kirchlich geforderte Frömmigkeit, indem er sich zynisch selbst zum Vermittler der Seligkeit ernennt. Gerade er bedarf ja der Kirche als eines Tarnungsinstruments, und nur unter seinesgleichen, hier gegenüber der sich sträubenden Lady Anne, der Witwe des von ihm gemordeten Edward, die er trachtet, als Ehefrau zu gewinnen - also nur innerhalb des Rudels, das um die Herrschaft streitet - zeigt er dosiert seine Raubtierqualitäten und was er von der Kirche wirklich hält. Übrigens gewinnt er am Ende die besagte Lady, die freilich nicht nur die Aussicht gereizt haben dürfte, mit dem verkrüppelten Scheusal Richard das Bett zu teilen.

Der Richard von Shakespeares ist freilich nicht der historische Richard. Dennoch, Einblicke in die Welt auch des historischen Richards verdanken wir gerade dieser Bühnenfigur Shakespeares, die wie keine andere seiner Charaktere so vertraut tut mit dem Publikum, von dem Shakespeare eben weiß, daß es seinem Richard so seelenverwandt ist. Wir selbst sind Buckingham, der stellvertretend für uns auf der Bühne das Gemeinwohl nur im Munde führt, um das eigene Streben nach Pfründen um so besser verbergen zu können. In diesem Sinne ist Shakespeares Richard III, sofern es das geben kann, reformiertes Theater par excellence, denn es entlarvt! Das soll aber nur das erste und nicht auch das letzte Wort zu dem sein, was das Reformiertentum zum Verständnis des Begriffs des Gemeinwohls beizutragen hat. Allein weil dieser ein metaphysischer Begriff ist insofern, als er eine Allheit bezeichnet und keinen empirisch überprüfbaren Sachverhalt, läßt er sich theologisch kritisieren. Es geht aber bei der Kritik des Begriffs hier nicht um ein besonderes Gemeinwohlverständnis, sondern um die Tauglichkeit des Begriffs als einer regulativen Idee für eine theologische Sozialethik überhaupt. Die soll nämlich bestritten werden, da dem zumindest das Verständnis der schweizer Reformation entgegensteht, die Kirche sei eine von Gott aus freier Gnade erwählte Gemeinschaft der Heiligen, und daß Gott zudem aus der Schar aller Menschen nur eine kleine Zahl für seine Kirche erwählt, die anderen aber, also die große Masse, verworfen habe. Gemeint ist die Lehre von der doppelten Prädestination des Calvinismus, die Max Weber für die Genese des kapitalistischen Geistes verantwortlich gemacht hat. Mit dieser Lehre und dem durch sie neu begründeten Selbstverständnis der Kirche läßt sich ein Verständnis des Gemeinwohls als einem sozial-ökonomischen Anliegen wohl kaum vermitteln. Andererseits kann natürlich auch nicht geleugnet werden, daß gerade der Calvinismus eine Vorstellung davon hatte und hat, wie die gesellschaftlichen Strukturen beschaffen sein sollten, in denen die Gemeinden ihren besonderen Auftrag zu erfüllen haben. Diese Vorstellung wurzelt aber letztlich in dem neuen Selbstverständnis der Gemeinde. Weil die Gemeindeauffassung von der Lehre der doppelten Prädestination geprägt ist, muß sie selbst kurz referiert werden, bevor in zwei weiteren Schritten das reformierte Gemeinwohlverständnis dargestellt werden kann, das sich mit den beiden Begriffen Bildung und Demokratie umreißen läßt. Dabei soll es weniger um die historische Entwicklung gehen, sondern um

3 Shakespeare, Richard III 1,2. 
systematische Überlegungen und Schlußfolgerungen für eine aktuelle Stellungnahme zum Allgemeinwohldiskurs aus der reformierten Prädestinationslehre.

\section{Die Erwählung}

Der Begriff des Gemeinwohls ist ein metaphysischer, schließlich ein politischer und damit ein polemischer Begriff. Er dient immer auch der Freund-Feind-Unterscheidung. Wer ihn gebraucht, erstrebt zugleich ein Interpretationsmonopol über ihn. Er dient zur Legitimierung von Herrschaft ebenso gut wie zu ihrer Infragestellung. Der Herr Omnes, wie Luther das nannte, in seiner alltäglichen Sorge, in dessen vorgeblichem Interesse das Gemeinwohl für gewöhnlich thematisiert wird, ist an der Formulierung dessen, was das Gemeinwohl sei, wenig beteiligt und wenig interessiert. Ihm kommt, wie Brecht das ausdrückte, das Fressen vor der Moral. Nicht selten ist der Gemeinwohlbegriff sogar gegen die materiellen Interessen des einfachen Volkes gerichtet, wenn etwa unter Berufung auf das allgemeine Wohl von dessen selbsternannten Sachwaltern dazu aufgerufen wird, Opfer zu bringen und Nachteile zu ertragen.

Gemeinwohldefinitionen sind Ausweise von Eliten, die entweder ihre Herrschaft zu legitimieren suchen oder die Herrschaft anderer Eliten in Frage stellen. Der Begriff des Gemeinwohls ist darum neben einem politischen auch ein elitärer Begriff. Es gibt keine Gesellschaft ohne Eliten. In der demokratischen Öffentlichkeit zeigen sich Eliten um das Gemeinwohl besorgt. Eliten sind, das sagt schon das Wort, auserwählt (lat. electio, Auswahl). Hier bietet sich nun ein weiterer Ansatz für eine reformiert-theologische und nicht alleine für eine nur sozialethische oder politische Betrachtung des Begriffs an. In der Geschichte der Kirche hat sich nämlich von je her eine Auffassung gehalten, daß sie, die Kirche, eine Gemeinschaft der Auserwählten sei, und zwar auserwählt von Gott ohne Ansehen eines menschlichen Verdienstes. Innerhalb der mittelalterlichen Kirche ist dieser Gedanke der Prädestination freilich nur gedacht, aber nie tatsächlich vertreten worden. Daß die Kirche überhaupt das sola gratia und damit die Rechtfertigungslehre vernachlässigte, machte sie erst zu einem geeigneten Partner für die Träger der politischen Macht, wie eingangs angedeutet. Die Erwählung wurde an Verdienste gebunden, die näher zu bestimmen sich die Kirche vorbehielt. Obwohl schriftgemäß, hat die Lehre von der frei geschenkten Gnade unter den bedeutenderen der mittelalterlichen Theologen nur Augustinus radikal durchdacht und vertreten. Spätere mittelalterliche Theologen, die ihm folgten, z. B. der Mönch Gottschalk, ${ }^{4}$ wurden unter Häresieverdacht gestellt. Erst mit der Reformation tritt diese Vorstellung wieder in den Vordergrund und wird nun von jenen Gruppen, die sie auf sich beziehen, als eine ihr Leben bestimmende Lehre angenommen. Jean Calvin hat die lutherische Rechtfertigungslehre eng mit der Lehre von der Prädestination und dem Gedanken der Heiligung verknüpft, und man spricht darum gerne vom Calvinismus, um jene Tradition zu bezeichnen, die sich unter anderem auch auf ihn beruft. Das ist nicht ganz korrekt, weil nicht die Person Calvins, sondern - gerade gemäß Calvins - die Ehre Gottes im Mittelpunkt jener Tradition ste-

4 Gottschalk von Fulda, 9. Jhd., wurde für sein Eintreten für die Lehre der doppelten Prädestination auf den Synoden in Mainz (848) und Quierzy (849) als Häretiker verurteilt. 
hen soll, die in Deutschland die reformierte heißt. Calvin hatte, um dies zu unterstreichen, sogar verfügt, daß er wohl ein Begräbnis, aber keine identifizierbare Grabstätte erhielt. Bleiben wir aber der Einfachheit halber bei Calvinismus, was insofern gerechtfertigt erscheint, weil Calvin unter den Reformatoren als derjenige gelten darf, der die doppelte Prädestination besonders betont hat.

Die Lehre läßt sich kurz wie folgt zusammenfassen: In der Institutio und anderen Schriften legt Calvin die Schrift dahingehend aus, daß Gott unter den Menschen, die auf Grund ihrer Sünde die Verdammnis als gerechte Strafe zu tragen haben, eine geringe Zahl zu seinem Dienst und seiner Verherrlichung erwählt hat, und zwar allein aus Gnade und ohne Ansehen eines Verdienstes, den es laut Calvin ebenso wie für die anderen Reformatoren für den Menschen vor Gott auch gar nicht geben kann. Abgesehen von der Erwählung der Wenigen treffe alle anderen Menschen verdientermaßen die Verdammnis, ohne daß die Betroffenen auf ihr Schicksal Einfluß nehmen könnten - weder die Erwählten noch die Verdammten. Darum spricht man von der doppelten Prädestination, der gemina praedestinatio. Die Absolutheit Gottes in seiner Wahl könne durch kein menschliches Werk eingeschränkt werden. Calvin führt zur Verteidigung der Prädestinationslehre zahlreiche biblische Stellen an, u. a. den Propheten Maleachi, der hier stellvertretend für die anderen zitiert sein soll: „Ist nicht Esau Jakobs Bruder? spricht der Herr; und doch hab ich Jakob lieb und hasse Esau“ (Mal 1, 2 u. 3). Diese Prädestination ist schon im Neuen Testament diskutiert worden, namentlich bei Paulus und im Johannesevangelium, und Paulus schreibt zu dem eben zitierten Vers unter gleichzeitigem Hinweis auf eine weitere Stelle in 2. Mose 33, 19, wo es heißt,

"Ich werde mich erbarmen, wessen ich mich erbarme, und werde barmherzig sein, gegen wen ich barmherzig bin“: „Somit kommt es nun nicht auf den an, der will, noch auf den, der läuft, sondern auf Gott, der sich erbarmt" (Röm 9, 14-16).

Es ist im Hinblick auf die soziale und politische Bedeutung der Prädestinationslehre vernachlässigenswert zu klären, ob Calvin sie in spekulativer oder in religiöser Absicht formuliert hat. Darüber ist in der reformierten Orthodoxie und besonders im Reformiertentum des 19. Jahrhunderts heftig gestritten worden. Man kann einmal von der Annahme der behaupteten totalen Abhängigkeit des Menschen von Gott und Gottes absoluter Freiheit her die Prädestinationslehre als logische Konsequenz spekulativ entfalten - was allerdings ein Unternehmen ist, vor dem Calvin immer wieder gewarnt hat, weil es dem Menschen nicht anstehe, dem Geheimnis Gottes zu nahe zu treten -; andererseits kann man aber der Prädestinationslehre auch eine religiöse Absicht unterstellen, womit gemeint ist, daß Calvin nach einer Erklärung dafür gesucht habe, warum sich so viele Menschen nicht der Reformation anschlossen, und daß Calvin das eben auf deren von Gott gewirkte Verstocktheit zurückgeführt habe. Vor allem aber habe die Prädestinationslehre den Gemeindegliedern die Gewißheit ihrer Erwählung vermitteln sollen Angesichts der Anfeindungen, denen die Reformation von Seiten einer Institution ausgesetzt war, die sich auf 1500 Jahre juridische Kontinuität berief, wäre dies ein nur allzu verständliches Anliegen. Wie dem auch sei, vernachlässigenswert ist diese Kontroverse, weil die religiöse die spekulative Interpretation nicht etwa ausschließt, sondern im Gegenteil voraussetzt und impliziert. Man entkommt dieser Implikation nicht, auch wenn man, wie Jürgen Moltmann in Deutschland oder Dewey D. Wallace in England, 
in Fortführung der religiösen Deutung die Lehre von der Perseveranz als den eigentlichen Kern der Prädestinationslehre behauptet ${ }^{5}$ oder wie Paul Jacobs die Prädestinationslehre als stets auf die Ethik bezogen betrachtet und glaubt, sie dogmatisch entsprechend vernachlässigen zu können. ${ }^{6}$ Das gilt gleichfalls für andere Aspekte der Prädestinationslehre wie etwa die Frage, ob Gott die Entscheidung über Erwählung und Verwerfung schon vor dem Fall des Menschen (Supralapsarismus) oder gar vor der Erschaffung der Welt (Supracreatianismus) getroffen habe. Die calvinistische Gemeinde jedenfalls repräsentiert dieser Lehre nach nicht irgend eine Elite, sondern die Elite schlechthin. Gleichwohl muß betont werden, daß die Implikationen der Prädestinationslehre nicht das Hauptanliegen Calvins und wohl auch nicht der calvinistischen Theologen der Zeit unmittelbar nach Calvins Tod in dem Maße waren, wie das bei Theologen der Orthodoxie und namentlich während der arminianischen Auseinandersetzungen der Fall wurde. Es sind dann aber gerade diese Implikationen, die im Verlauf der Säkularisierung und der Verbürgerlichung von Gesellschafen, die von der reformierten Tradition maßgeblich geprägt wurden, sozial und politisch wirkten. Schon Max Weber bemerkte in seinen Untersuchungen über die calvinistische Ethik: , $[U]$ nvorhergesehene und geradezu ungewollte Folgen der Arbeit der Reformatoren waren [...] oft weit abliegend oder geradezu im Gegensatz stehend zu allem, was ihnen selbst vorschwebte “" ${ }^{7}$ Andererseits ist die Prädestinationslehre aber im Hinblick auf ihre gesellschaftlichen Konsequenzen von Anfang an bekämpft worden, denn ihre sozialen und politischen Folgerungen lagen auf der Hand und waren den Reformatoren auch durchaus bekannt, wurden aber eben nicht von allen bejaht.

Die spontane Ablehnung der Prädestinationslehre erfolgt in der Regel auf Grund eines Mißverständnisses dessen, zu was die Gemeinde sich als erwählt zu betrachten habe. Es geht, um es kurz zu sagen, und hier folge ich der Richtung der Interpretation von Jacobs, um das rechte Verständnis des Gesetzes, und besonders um seinen nach lutheranischer Zählung dritten Gebrauch, den tertius usus oder auch usus in renatis. Im ersten Gebrauch, im usus politicus bzw. paedagogicus legis, dient das Gesetz zur Aufrechterhaltung der äußeren Ordnung. Der zu Beginn seines reformatorischen Wirkens noch antinomistische Luther hat diese Bedeutung des Gesetzes im antinomistischen Streit gegen Agricola und andere Antinominianer betont, nachdem die ersten Visitationen der neuen lutherischen Gemeinden gezeigt hatten, daß dem Sittenverfall dringend entgegengetreten werden mußte. Im usus elenchticus dient das Gesetz zur Erkenntnis der Sünde und der Angewiesenheit des Sünders auf die Gnade Gottes, weil der Mensch angesichts der Forderungen des Gesetzes anerkennen müsse, daß er das Gesetz zu erfüllen nicht in der Lage sei. Der usus in renatis vermittelt dagegen die Erkenntnis des Willens Gottes für die Gemeinde der Erwählten. Das Gesetz hält also auch und gerade dem Gläubigen die fortlaufende Forderung Gottes vor. Erwählt ist der Mensch nach Calvin nicht alleine zu einem zukünftigen und jenseitigen Heil, sondern zunächst in der Welt zum Dienst in der Freiheit der Kindschaft Gottes. Von daher ist für Calvin der dritte Gebrauch des Geset-

5 Vgl. Moltmann 1961 u. Wallace 1982.

6. Jacobs 1937.

7 Weber 1988, S. 82. 
zes, den Luther nicht betont, eigentlich der erste. ${ }^{8}$ Dienst ist diesem Verständnis nach eine existentiale Bestimmung des Menschen, d. h. daß der Mensch nicht als ein Wesen betrachtet wird, das einmal dient und einmal nicht dient, sondern daß dessen Seinsverfassung Dienst ist. Das sieht das Luthertum (nicht unbedingt Luther, von dem ja das Bild vom Menschen als einem Reittier stammt, das entweder von Christus oder vom Teufel geritten werde) anders. Adolf Köberle, ein lutherischer Theologe und Schüler Karl Heims, ${ }^{9}$ interpretiert die Rechtfertigungslehre gemäß der Konkordienformel so, daß mit der Rechtfertigung der Mensch in einen supralapsarischen Zustand gebracht werde, in dem er die Freiheit besitze, die Gnade Gottes anzunehmen oder abzuweisen. ${ }^{10}$ Calvin dagegen betrachtet auch die guten Werke der Heiligung als vom Geist gewirkt, wie auch das Beharren im Glauben, die Perseveranz. Jürgen Moltmann formuliert das, gleichzeitig den Begriff des Geistes erläuternd, wie folgt: „Nicht des Menschen subjektive Standhaftigkeit leistet das Bleiben, sondern die von Christus gestifteten neuen Verhältnisse, in denen er selber neu wird". ${ }^{11}$ Dienst und Freiheit bedingen sich dann insofern, als im Gottesdienst der Mensch frei wird gegenüber den Ansprüchen der Mächte der Welt, die ihn ebenfalls ganz und gar haben und beanspruchen wollen. ${ }^{12}$ Die innerweltliche Askese wird nicht im Hinblick auf ein Heil geübt, um sich ihm gegenüber zu bewähren, sie ist selber schon das Heil. Der von Gott in Dienst genommene Mensch steht damit grundsätzlich in einem Spannungsverhältnis zu jeder Form von Herrschaft, die ihn ihrerseits in Dienst nehmen will. Der Mensch dient also immer, aber insofern er Gott dient, ist er gegenüber den Ansprüchen aller anderen Mächte frei. Weil er diese Freiheit nicht selber wählen kann, da diese Wahl ja gerade diese Freiheit voraussetzte, muß er zu ihr als erwählt betrachtet werden. Sie zu wahren ist dann gerade sein Dienst, sein Gottesdienst in der Welt, d. h. sein Gehorsam gegenüber dem ersten Gebot, den der Geist in ihm bewirkt. Denn die Freiheit hat diesem Verständnis nach nicht den individuellen Menschen zum Subjekt, der alleine seine Freiheit nicht zu sichern vermag. Das Subjekt der Freiheit und damit das Objekt der Befreiung ist die Gemeinde. Gottesdienst ist niemals ein individuelles, sondern ein gemeinschaftliches Unternehmen. Der Mensch ist befreit in die Teilhabe an der herrlichen Freiheit der Kinder Gottes - und das nicht in einen Moment der Wahl, wie auch das erste Gebot betont: „Ich bin der Herr, dein Gott, der ich dich aus dem Lande Ägypten, aus dem Sklavenhause, herausgeführt habe“ (Ex 20,2). Das Gesetz

8 Gleichwohl Calvin in der ,Institutio“ (1988a) zunächst den usus elenchticus, dann den usus politicus und erst an dritter Stelle den usus in renatis abhandelt.

9 Köberle: geb. 1898, gest. 1990; ab 1930 Professor in Basel, ab 1939 in Tübingen.

${ }^{10}$ Köberle 1929, bes. S. $171 \mathrm{ff}$. Vgl. dazu die entsprechende Stelle in der Konkordienformel: „Darumb ist ein großer Unterschied zwischen den getauften und ungetauften Menschen; denn weil nach der Lehre S. Pauli, Gal.3, ,alle die, so getauft sind, Christum angezogen' und also wahrhaftig wiedergeboren, haben sie nun arbitrium liberatum", in: Die Bekenntnisschriften der evangelischlutherischen Kirche 1959, S. 898.

11 Moltmann 1961, S. 51.

${ }^{12}$ Für das Luthertum läßt sich, wie Werner Elert schreibt, „das Ethos nicht aus den Begriffen der Freiheit, des Nächsten und der Liebe deduzieren [...] Es fehlen dabei die schicksalhaften Faktoren. [...] Ist aber Ethos niemals nur Qualität des einzelnen, sondern stets überindividuelle Beziehung, so können diese Dinge auch niemals dabei ausgeschaltet werden. Das Ethos vollzieht sich vielmehr stets im Rahmen der Schöpfungsordnungen", Elert 1953, S. 48. 
ist im Verständnis des tertius usus legis die Freiheitsordnung Gottes. Bei Luther fehlt dagegen sowohl im Großen Katechismus als auch im Kleinen Katechismus dort, wo er das erste Gebot erklärt, der Freiheitszuspruch, er unterschlägt ihn im Zitat des ersten Gebots. Das reformierte Verständnis des Gesetzes hat somit nicht nur Auswirkungen auf die Liturgie, auf den, bedenkt man den ursprünglichen Sinn von $\lambda \varepsilon \iota \tau o u \rho \gamma \iota \alpha$, öffentlichen Dienst der Gemeinde. In diesem Zusammenhang sei darauf hingewiesen, daß Hasso Hofmann im Hinblick auf das moderne Rechtsverständnis bemerkt hat, in der Neuzeit begründe mitnichten die Idee der Gerechtigkeit, wie zuvor über Jahrhunderte hinweg, das Recht, sondern zunächst die der Sicherheit und die des Friedens, mit und nach Kant aber zuvörderst die der Freiheit ${ }^{13}$ - und daß sogar das Kommunistische Manifest nicht ein Reich der Gerechtigkeit, sondern das der Freiheit verheiße. ${ }^{14}$ Die Freiheit der Kinder Gottes aber verdankt sich dem reformierten Verständnis nach der freien Gnadenwahl und damit der besonderen Gerechtigkeit Gottes, die nach menschlichem Ermessen freilich als ungerecht empfunden werden muß - summum jus, summa injura. Im Reformiertentum bahnte sich so ein Verständnis von Freiheit den Weg, das insofern nicht im Widerspruch zum modernen Verfassungsverständnis steht, als hier der vereinzelte Mensch mit den anderen isoliert betrachteten Freien nicht erst wieder in einem weiteren Schritt vermittelt werden muß. Das hat dann die entsprechenden Auswirkungen auf das Gemeinwohlverständnis.

\section{Einwände gegen die Prädestinationslehre unter Berufung auf das Gemeinwohl}

Auf den ersten Blick scheint es schlüssig zu sein, Gesellschaften, in denen der Calvinismus die bestimmende Konfession geworden ist, in irgend einem Sinne als aristokratisch verfaßt anzunehmen. Es ist dem Calvinismus von lutherischer Seite auch entsprechend bestritten worden, überhaupt ein Gemeinwohlbewußtsein zu haben. Als Beispiel für viele soll hier der Göttinger Anglist und Religionssoziologe Herbert Schöffler dienen: „Die Kehrseite [der Prädestinationslehre - M. E.] konnte eine um so stärkere Vernachlässigung derer sein, die nach allem menschlichen Ermessen, nach allen sichtbaren Zeichen zu der geringen Schar der Auserwählten nicht gehören konnten". ${ }^{15}$ Erst das Luthertum habe dem Puritanismus ${ }^{16}$ ein soziales Gewissen zu vermitteln vermocht. John Wesleys Glaubenskrise etwa sei während seines Besuchs der Londoner Herrnhuter Gemeinde anläßlich eines Vortrags über Luthers Einleitung in den Römerbriefkommentar überwunden worden: „Das Ereignis vom Mai 1738 bedeutete nichts anderes als den Sieg Luthers über Calvin im englischen Felde" ${ }^{\text {17 }}$, schreibt Schöffler. Über die methodistische Erweckungsbewegung seien

${ }^{13}$ Hofmann 2000, S. 34 ff.

${ }^{14}$ Ebd., S. $193 \mathrm{ff}$.

15 Schöffler 1960, S. 330.

${ }^{16}$ Den Schöffler mit dem Calvinismus gleichsetzt.

17 Schöffler 1960, S. 330. 
„die Presbyterianer Englands, die Kongregationalisten, die Baptisten und Quäker, die Evangelikalen in der Staatskirche, die gesamte Low-Church-Richtung, späterhin die United Free Church Schottlands nach Luther hingekehrt (worden) " 18

So seien es in England gerade jene nach der Glorreichen Revolution aus dem politischen Leben ausgeschlossen Gemeinschaften gewesen, die die sozialen Bewegungen gegen die Sklaverei, für die Gefängnisreform, für die Reform der Psychiatrie, für die Verbesserung der Lage der arbeitenden Klasse, für ein Schulsystem und schließlich für die Emanzipation der Frauen initiiert hätten.

Diesen sozialen Puritanismus, das ist die Pointe von Schöfflers Überlegungen, habe es in Deutschland nicht gegeben, und zwar weil Deutschland ihn auch gar nicht nötig gehabt habe. Schöffler stützt sich auf eine Passage aus Adam Smiths The Wealth of Nations: Darin bezeichnet Smith die Sklaverei in den französischen Kolonien darum als humaner als jene unter den Engländern, weil bei ersteren der Staat nicht selber Sklavenhalter sei, in den englischen Kolonien die Sklavenhalter sich aber selber beaufsichtigten. ${ }^{19}$ Schöffler urteilt: „Das Allumfassende, die alle menschlichen Beziehungen einhergreifende Sorge des absolutistischen Staates steht plötzlich in unerwartetem Lichte da", und weiter, bezogen nun auf Deutschland:

„Wo immer die Gefahren auftauchen, die in derselben oder ähnlichen Gestalt dem englischen Volke verhängnisvoll geworden sind, war bei uns die Initiative des Beamtenstaates wach und ist dem Drohenden früh entgegengetreten." .20

Das Fazit der Schöfflerschen Überlegungen liegt auf der Hand: Dem sozialen Ungleichgewicht in England, für das maßgeblich der Puritanismus und damit die calvinistische Konfession verantwortlich gemacht wird, habe nur unter Berufung auf Luther begegnet werden können.

Tatsächlich ist die Reformation in England, die Heinrich VIII bekanntlich nicht wünschte und die er, sofern er sie nicht politisch instrumentalisierte, bekämpfte, unter dessen Sohn Edward VI (Edward dem Kind) radikalcalvinistisch durchgeführt, vom einfachen Volk aber größtenteils abgelehnt worden. Der Herrschaftsantritt von Heinrichs Tochter aus der ersten Ehe, Mary, der später so genannten Bloody Mary, wurde darum von Vielen begrüßt, sogar aus den Reihen der Geistlichkeit. Unter den Pfarrern, die wegen ihrer mittlerweile geschlossenen Ehen belangt worden seien, habe es wohl auch manche gegeben, bemerkt Schöffler süffisant, „, die ihr Gespons in vier- bis sechsjähriger Ehe hinlänglich kennengelernt hatten, um sich für die Segnungen des Zölibats in ganz neuem Sinne zu interessieren" ${ }^{21}$ Wie dem auch gewesen sein mag, für Schöffler ist zwar die Kirche das soziale Gewissen des Staates, die Verhältnisse aber sollen bleiben, wie sie sind. Schöffler ist wie einer von den Bischöfen, die Shakespeares Richard die Weihe geben.

Aber auch vielen Reformierten erscheint die Prädestinationslehre, insbesondere natürlich die Lehre von der doppelten Prädestination, als nicht mehr zeitgemäß. Jan Rohls

\footnotetext{
18 Ebd., S. 331.

19 Vgl. Smith, Wealth of Nations, 4. Buch 7. Kapitel.

20 Schöffler 1960, S. 348, 351.

${ }^{21}$ Schöffler 1960, S. 291.
} 
etwa erklärt, sie sei mitnichten ein zentrales Dogma des Reformiertentums, ${ }^{22}$ und Bernard Cottret, der Autor der jüngsten Calvinbiographie, schreibt: „Pauvre Calvin, victime de son système. La prédestination est devenue le loup-garou de la théologie réformée. On ne s'en approche qu'avec effroi““. ${ }^{23}$ Schon John Milton, der Dichter von Paradise Lost, erklärte: „Mag ich zur Hölle fahren, aber solch ein Gott wird niemals meine Achtung erzwingen“. ${ }^{24}$ Aber andererseits hat es bedingungslose Anhänger der Lehre von der doppelten Prädestination gegeben, besonders in England. Dewey D. Wallace glaubt sogar, eine gewisse Neigung des englischen protestantischen Denkens hin zur Prädestinationslehre im Sinne der doppelten Prädestination ausmachen zu können, insbesondere wegen ihrer antiinstitutionellen Ausrichtung. Sie werde jedenfalls schon in der frühen englischen Reformationsliteratur, etwa bei William Tyndale und John Frith, vertreten, und gerade sie beherrsche die Edwardianische Reformation. In der Zeit der Regentschaft der Bloody Mary sei sie von den Verfolgten bis in die Kerker hinein verteidigt worden, auch gegen die eigenen Mitbrüder, die sie nicht mehr ernstgenommen hätten. Wallace führt John Bradford als Zeugen an, der einigen Abweichlern, sogenannten freewillers, schrieb:

\begin{abstract}
"Although I look hourly for officers to come and have me to execution, yet can I not but attempt to write something unto you, my dearly beloved [...], to occassion you the more to weigh the things wherein some controversy hath been amongst us, especially the article and doctrine of predestination, whereof I have written a little treatise [...]. Only by the doctrine of it I have sought, as to myself, so to others, a certainty of salvation, a setting up of Christ only, an exaltation of God's grace, mercy, righteousness, truth, wisdom, power and glory, and a casting down of man and all his power. ${ }^{625}$
\end{abstract}

Was muß diese Lehre, die so abgründig scheint und die einen Bernardino Ochino sogar zu der Behauptung führte, Christus selber könne einen Verdammten nicht retten - was nebenbei gesagt ein nicht gerade schmeichelhaftes Licht auf die Christologie des besagten Herren wirft - jenen Männern im Kerker bedeutet haben? ${ }^{26}$ Es ist, neben den religiösen Gründen, auch die mit dieser Lehre verbundene Ablehnung jeglicher Herrschaft, die sich auf Verdienste beruft, wobei sich die Prädestinationslehre gleichzeitig selber einer Rechtfertigung gleich welcher Herrschaft auch immer versagt: Neben der Perseveranz, die auch er in den Vordergrund stellt, ${ }^{27}$ betont Wallace noch:

"Nor can predestination mean license, for it is an election to holiness, taking away pride in merits, provoking piety and , a true desire of our home in heaven', and encouraging contempt for worldly things as well as service of the neighbor and care for God's glory. ${ }^{628}$

22 Vgl. Rohls 1999.

23 Cottret 1998, S. 329.

${ }^{24}$ Zit. n. Weber 1988 , S. 91

25 Wallace 1982, S. 22.

${ }^{26}$ Ebd., S. 16; Ochino radikalisierte sich und wandte sich dann gegen die Prädestinationslehre.

27 „The theology of predestinarian grace was ultimately rooted in a particular piety or way of being religious; it was the reflection of a religious experience." Wallace 1982, S. 194.

${ }^{28}$ Wallace 1982, S. 23. 
Die politischen Folgen liegen auf der Hand: Während der englischen Revolution unterstützte Charles I die Arminianer, ${ }^{29}$ jene Reformierte, die die Lehre von der doppelten Prädestination bekämpften und über die Wallace urteilt:

„For the English Arminians can be described as ,high church“ or even ,Anglo-Catholic', emphasizing the sacraments as channels of divine grace [...]. Sacramentalism meant the exaltation of priesthood and episcopacy [...] And in the case of the Laudians, divine right episcopacy was closely related to divine right monarchy. ${ }^{630}$

Mit den Laudians sind jene Anhänger des William Laud gemeint, der unter der Regentschaft Charles I zunächst Bischof in London und später Erzbischof in Canterbury war, und der die Arminianer nachhaltig unterstütze. Auch in den Niederlanden vertraten die Arminianer ein Staatskirchentum.

Wo die Reformation mit monarchischen Interessen verschmolz, gab es keinen Platz mehr für einen Gedanken an die Prädestinationslehre. Selbst im Heidelberger Katechismus findet sie keine ausdrückliche Erwähnung mehr. Jan Rohls schreibt über Heidelberg als Zentrum der innerprotestantischen Unionsbestrebungen im Zeitalter der Refomation und der sich anschließenden konfessionellen Auseinandersetzungen und Kriege im Reich, freilich ohne daß er auf Grund seiner Beobachtung die besagte Lehre sympathischer fände:

„Natürlich stand im Hintergrund das macht- und sicherheitspolitische Interesse der Kurpfalz, die über enge dynastische Beziehungen zu den Niederlanden und England verfügte und bis zur Niederlage des Winterkönigs die Vormacht der antikatholischen Front im Reich war. ${ }^{\text {"331 }}$

$\mathrm{Ob}$ es der geforderten Kürze seiner Broschüre geschuldet ist, daß Rohls hier die Kurpfalz mit dem kurfürstlichen Hof identifiziert, wenn er über sie schreibt, sie verfüge über dynastische Verbindungen usf.? Es führt zu weit, darüber zu spekulieren, wer heute alles im Solde Charles I stünde. Doch in jedem Charles steckt ein Richard. Die reformierte Konfession hat in Deutschland keine Wurzeln bilden können, weil in Deutschland die Reformation eine Angelegenheit der Höfe hat sein müssen, weil es keine republikanische Alternative gab. Dort, wo das Reformiertentum sich hat halten können, wurde es verwässert und schließlich sogar nicht mehr verstanden, denn die Prädestinationslehre steckt implizit auch im Heidelberger Katechismus. ${ }^{32}$

29 Jacob Arminius (eigentlich Harmensz), 1560 bis 1609. Arminius lehrte, in Christus sei allen Menschen die Versöhnung mit Gott angeboten, aber nur die Glaubenden hätten Teil an ihr. Der Mensch könne sich sowohl auf die Gnade vorbereiten als auch vom Glauben abfallen. Arminius trat für eine niederländische Staatskirche ein. Seine Lehre wurde auf der Synode von Dordrecht 1618 als Häresie verurteilt. Die gleiche Synode entschied aber, die Prädestinationslehre infralapsarisch zu verstehen.

30 Wallace 1982, S. 98.

${ }^{31}$ Rohls 1987, S. 12.

${ }^{32}$ Man beachte besonders die Frage 20, 53 und 54: „Werden denn alle Menschen wiederum durch Christus selig, wie sie durch Adam sind verloren worden? Nein, sondern allein diejenigen, die durch wahren Glauben ihm werden eingeleibt und alle seine Wohltaten annehmen" (20). Frage 53 nennt den HI. Geist als Mittler des Glaubens, und Frage 54 bekennt, daß „der Sohn Gottes aus dem ganzen menschlichen Geschlecht sich eine auserwählte Gemeinde zum ewigen Leben durch seinen 
Der Calvinismus revolutioniert die Gesellschaft, indem er die Selbstreproduktion von Eliten zu unterbinden trachtet. Das macht ihn grundsätzlich attraktiv für aufstrebende Gesellschaftsschichten. Es überrascht darum nicht, daß gerade in den calvinistisch geprägten Gesellschaften die Demokratie im neuzeitlichen Sinne ihre Begründung fand. Die Perhorreszierung der Prädestinationslehre dient dagegen nicht selten der Abwehr einer Delegitimierung bestehender Eliten, besonders der von Bildungseliten, und sie beruft sich dabei nicht selten auf das liberale Menschenbild. Dabei wird aber das eigentliche liberale Verständnis dieser Lehre, und zwar liberal im Sinne von freiheitlich, unterschlagen. Diesem Freiheitsverständnis nach ist Freiheit zunächst als Freiheit von Traditionen zu verstehen, die einer Vergesellschaftung des Menschen, d. h. seiner Sozialisation, im Wege stehen.

\section{Prädestination und Familie}

Die Prädestinationslehre wendet sich zunächst einmal eigentümlich gegen die Familie, was den Blick auf das reformierte Gemeinwohlverständnis eröffnet. Denn die Sorge für die Familie, nicht der Egoismus des abstrakten Einzelnen, beeinträchtigt für gewöhnlich den Gemeinsinn, der zum Engagement für das Gemeinwohl motiviert. Wo Herrschaft sich über Familientraditionen legitimierte, hatte die Prädestinationslehre keine Chance auf Anerkennung.

In der Sorge um das Familienleben formierte sich darum auch innerhalb der reformierten Gemeinden der Widerstand gegen die Lehre von der Prädestination. Fehlt nämlich der Gemeindebezug, und die Gemeinde ist verstanden als der auferstandene Leib des Herrn, vereinzelt die Prädestinationslehre den Menschen auf eine unerträgliche Weise, besonders gegenüber und innerhalb der Familie als seinem natürlichen Umfeld. Dies ist ein weiterer Beleg dafür, daß man reformiert nur in der Gemeinschaft einer Gemeinde sein kann. Fehlt dieser Bezug, wird aus der Prädestinationslehre eine in sich unsinnige, abgöttische Doktrin, die dem ursprünglichen Verständnis, nämlich der Vereinzelung zu wehren, gerade zuwiderläuft. Daraus, daß unser Blick nur auf den einzelnen Menschen gerichtet ist und er alleine als das Objekt der Erwählung betrachtet wird, ergeben sich die meisten Mißverständnisse über die Lehre. Cottret z. B. bemerkt auf Grund seiner Sentimentalität für das einzelne, dem liberalen Denken sakrosankt geltende Individuum, schon Calvin selber habe den Familien gegenüber Zugeständnisse gemacht: „Le calvinisme ultérieur tempère la prédestination, en insistant sur son caractère lignager [es folgt ein Verweis auf den Dordrechter Kanon von 1618/19; Anm. M. E.]" ${ }^{33}$ und weiter: „Cette dérive familiale est déja amorcée par le Réformateur“ ${ }^{34}$ Doch die Stelle, die Cottret als Beleg anführt, kann überhaupt nicht überzeugen. Cottret bezieht sich nämlich auf eine Predigt Calvins über Hiob, wo Calvin gerade nicht die Erwählung, sondern den Zorn Gottes sich von den Eltern auf die Kinder fortsetzen sieht. Aber

Geist und Wort, in Einigkeit des wahren Glaubens von Anbeginn der Welt bis ans Ende versammle, schütze und erhalte und daß ich derselben ein lebendiges Glied bin und ewig bleiben werde."

33 Cottret 1998, S. 312.

34 Ebd., S. 313. 
der Zorn ist ja gerade das, was der Mensch von Adam an verdient, von hier aus ist ein Analogieschluß auf die Erwählung völlig widersinnig. Cottret hätte sich allenfalls auf Calvins Tauflehre berufen können, wo es in der Absicht, die Säuglingstaufe gegen die Wiedertäufer zu verteidigen, heißt:

„(D)as Zeichen Gottes, das einem jungen Knaben gegeben wird, bekräftigt wie ein aufgedrücktes Siegel die Verheißung, die dem frommen Vater oder der frommen Mutter gegeben ist, und erklärt es für abgemacht, daß der Herr nicht nur der Gott des Vaters oder der Mutter, sondern auch der Gott ihres Samens sein [...] will, [...] ihren Nachfahren bis ins tausendste Glied. ${ }^{635}$

$\mathrm{Daß}$ die Erwählung eine Erwählung zum Dienst ist, wird freilich auch hier betont, wenn Calvin anfügt:

„Und wenn sie dann herangewachsen sind, so werden sie durch ihre Taufe nicht wenig zum ernsten Trachten nach der Verehrung Gottes angespornt, der sie ja durch das feierliche Merkzeichen ihrer Adoption zu Kindern angenommen hat $[\ldots]^{\text {‘c } 36}$

Aber hier ist größte Vorsicht geboten, das Mißverstehen der Stelle resultiert daraus, daß man sie isoliert und ihren Kontext übersieht: Wohl argumentiert Calvin in der Tauflehre der Institutio gegen die Wiedertäufer, indem er die Taufe analog zur Beschneidung versteht, womit er das Argument zu entkräften sucht, die Kindertaufe sei nicht biblisch. Doch die Taufe verpflichtet zunächst einmal die Gemeinde, weil nicht sie, sondern Gott das Ja gegenüber dem Kinde und den Eltern ausspricht, und die Gemeinde in diesem Glauben zu leben hat. Mit der Taufe anerkennt die Gemeinde diesen Sachverhalt. Sie verfügt nicht selbst über sich und ihre Gestalt. In seiner Prädestinationslehre hat Calvin dagegen die Vorstellung eines Samens der Erwählung ausdrücklich abgelehnt.

„Einige träumen da nämlich, in ihr Herz sei von Geburt an wer weiß was für ein ,Same der Erwählung' eingesenkt, durch dessen Kraft sie stets zur Frömmigkeit und zur Furcht Gottes geneigt wären; aber sie haben keine Stütze an der Autorität der Schrift und werden auch durch die Erfahrung selbst widerlegt. ${ }^{\text {‘37 }}$

In De aeterna Dei praedestinatione argumentiert Calvin gegen Albert Pighius, einen Utrechter Gegner der Prädestinationslehre, der seine Kritik damit begründete, durch die Taufe könnten dann auch Verbrecher zur Schar der Erwählten stoßen; Calvin antwortet:

„Wie Paulus eine Beschneidung nach dem Buchstaben und eine nach dem Geiste annimmt (Röm 2,27ff), so muß man auch von der Taufe denken, daß einige das Zeichen nur nach dem Buchstaben an ihrem Körper tragen, die von der Sache weit entfernt sind. ${ }^{638}$

Was so sehr der natürlichen Liebe der Eltern gegenüber ihren Kindern widerspricht, das ist für privilegierte Familien unannehmbar, eröffnet aber gerade den Nachkommen unterprivilegierter Familien gesellschaftliche Aufstiegschancen. Das Reformiertentum kennt im Unterschied zum Luthertum keine Schöpfungsordnungen. Der Ehe wird zwar

${ }^{35}$ Calvin 1988a, Institutio 4,16,9.

${ }^{36}$ Institutio 4,16,9.

${ }^{37}$ Institutio 3,24,10.

${ }^{38}$ Calvin 1998b, S. 77. 
eine gewisse Bedeutung beigemessen, weil sie als Bund den Gottesbund illustriert, aber eben nur der Ehe, nicht der Familie. Alfred de Quervain, der als der bedeutendste Ethiker der reformierten Theologie des 20. Jahrhunderts gelten darf, schreibt:

„Eine theologische Ethik kann ihre Arbeit nicht so beginnen, daß sie autonome ethische Prinzipien übernimmt, daß sie auf die ethischen Formen der Ehe und der Familie zurückgreift, die dem denkenden Menschen bekannt seien, daß sie auf die Idee der Ehe sich beruft",

und weiter:

„Es wird bezeugt, daß der Mensch in der Ehe und in der Familie weder sich selbst lebt noch für eine Ordnung da ist “. ${ }^{\text {. }}$

Die Familie wird darum auch nicht, wie im Luthertum, als die Keimzelle der Gemeinde betrachtet. Entsprechend betont de Quervain, bevor er auf die Kinder zu sprechen kommt, daß die Ehe als Bund ihren Zweck nur in sich selber finde, daß er nicht außerhalb ihrer liege: „So sind auch die Kinder nicht Zweck der Ehe“, ${ }^{40}$ heißt es, und schärfer noch: „Hinter dieser Verkennung des Wesens der Ehe steckt Mißachtung der Güte Gottes, eine Knechtsgesinnung “ ${ }^{41}$ Erst nach dieser Klarstellung erfolgt dann der Hinweis, daß auf der anderen Seite gewollte Kinderlosigkeit wiederum nichts anderes sei als ein Verjagen der Kinder, aber wesentlich bleibe: In der Ehe und in der Familie gehe es primär darum, im Glaubensgehorsam zu leben. Alfred de Quervain hat in seiner Ethik das Leibliche, auch die leibliche Abstammung der Kinder von den Eltern, nicht als unbedeutend beiseite geschoben, aber er schreibt sehr deutlich über diese Beziehung, die nicht selten mit dem Satz „Blut ist dicker als Wasser" betont wird:

„Das Leibliche ist nicht Nebensache, aber es ist nicht in sich selbst sinnvoll. [...] Der von Menschen Geborene, ein Lebewesen unter anderen Lebewesen, lebt nicht von dem, was seine Eltern in der Geburt und durch Erziehung ihm zu geben vermögen. Er ist nicht das, was er aus dem Empfangenen macht, was die Verhältnisse aus ihm machen. Sein eigentliches Leben hat er als ein von Gott Gerufener. ${ }^{\text {"4 }}{ }^{2}$

Gerufen ist er aber, das zu betonen darf man nicht müde werden, in den Dienst und damit in die Freiheit der Gemeinde Christi.

Es wäre das Eine oder Andere noch hinsichtlich dessen zu sagen, wie diese Sicht der Ehe das Familienleben zu entlasten vermag, aber allein die Folgerungen für das Gemeinwohlverständnis, die gesellschaftlichen Implikate, interessieren hier: Kurz gesagt, mit Hilfe der Lehre von der doppelten Prädestination lassen sich keine Maßnahmen rechtfertigen, die zu einer Selbstrekrutierung von Eliten über die Familie führen, im Gegenteil: Die Lehre von der doppelten Prädestination ist ein Angriff auf alle Maßnahmen, die es einer Elite ermöglichen sollen, sich selber zu reproduzieren.

\footnotetext{
39 De Quervain 1953, S. 43, 44.

40 De Quervain 1953, S. 78.

${ }^{41}$ Ebd., vgl. Elert 1953, S. 84, der unter Berufung auf Luther schreibt: „Daß Gott durch die Ehe geehrt werde, ist sittliche Aufgabe des Menschen. Es geschieht durch Kinderzeugen, das nächst dem Predigen das höchste Werk ist."

${ }^{42}$ De Quervain 1953, S. 158 u. 160.
} 
So mußte in den schweizer Städten, die sich den Evangelischen angeschlossen hatten, namentlich in Zürich und in Genf, die Reformation gegen den Widerstand alteingesessener und mächtiger Familienclans durchgesetzt werden. ${ }^{43}$ Die Reformatoren hatten entsprechend ein großes Interesse an der Sozialisation der Familien. Die Loyalitätsebenen mußten neu definiert werden. Zuerst die Treue zum Bekenntnis, zum Leben der Gemeinde, dann, und auf keinen Fall gegen das Bekenntnis zur Gemeinde als dem auferstandenen Leib des Herrn, die Loyalität gegenüber der Stadt.

\section{Bildung}

Gemeinwohl meint im Reformiertentum primär Bildung, und zwar Bildung für möglichst alle Menschen, weil alle einen über den Ruf in den Dienst in der Gemeinde sich begründenden Bildungsanspruch haben. Das scheint zunächst dem Prädestinationsgedanken zu widersprechen, aber der Bildungsanspruch aller ist darin begründet, daß der Ruf sowohl an die Erwählten als auch an die Verworfenen ergeht, die zu unterscheiden der Mensch sich ja nicht anmaßen darf.

Der Bildungsgedanke spielt in der gesamten Reformation, natürlich auch bei Luther, eine ganz besondere Rolle. Er steht in unmittelbarem Zusammenhang mit der Entdekkung des Individuums, das sein Heil dem reformatorischen Verständnis nach nicht mehr der Vermittlung einer kirchlichen Instanz verdanke. Entsprechend sei das Individuum auch keiner kirchlichen Instanz mehr zu unterwerfen, sondern als allein seinem Gewissen unterworfen zu betrachten. Die Distanz gegenüber Herkunft und Familie war eine unabdingbare Voraussetzung für die Entwicklung der individuellen Gewissensvorstellung. Das Gewissen sollte nicht mehr an die Familienehre und an die Werte anderer traditioneller Gemeinschaften gebunden werden, sondern rational gestalteten Gesellschaften gegenüber verpflichtet werden, namentlich gegenüber den entstehenden staatlichen Verwaltungen und einem zunehmend expandierenden Markt. In dem Maße, wie die Bewährung im Alltag und damit die Arbeit als Gottesdienst verstanden wurde, ging es bei der Gewissensbildung von nun an nicht mehr um die Verankerung von bestimmten Verhaltensnormen, sondern um die Herausbildung einer durchaus flexiblen Grundhaltung, eines Ethos, der der sich stetig verändernden gesellschaftlichen Wirklichkeit gerecht werden konnte. Die individuellen Gewissen zu gestalten, so glaubte man entsprechend, bedürfe es einer Bildung, die im Interesse der Sozialisierung des Menschen nicht mehr der Familie überlassen werden dürfe. Über die Bildung des Gewissens sollte die Ausrichtung des Handelns auf das Allgemeinwohl erreicht werden, das wiederum $\mathrm{zu}$ erkennen überhaupt erst dem Gebildeten gestattet sei. Es hat von daher von Anfang

${ }^{43}$ Zwingli ließ Prozesse gegen einige führende Familien Zürichs führen, bei denen einer zum Todesurteil gegen Jakob Grebel führte. Eine der Hauptanklagepunkte war das Annehmen von Pensionen aus dem Reislaufen, dem früher einmal geleisteten Söldnerdienst, den viele Schweizer dem Ausland leisteten und aus dem sich über die Geldzahlungen bleibende Loyalitäten ergaben; vgl. Locher 1979. Im Genf Calvins diente insbesondere die Kirchenzucht dazu, den Widerstand der alteingesessenen Familien zu brechen. Diese Politik konnte sich aber der Unterstützung der vielen Flüchtlinge sicher sein, die in Genf Zuflucht vor Verfolgung fanden. 
an eine Beziehung zwischen Humanismus und Reformation gegeben, aber sie war spannungsvoll. Luther schätzte wohl die philologischen Resultate humanistischer Forschung, aber er bestritt in seiner Schrift gegen den freien Willen die von Erasmus von Rotterdam behauptete Möglichkeit der sittlichen Besserung des Menschen durch Bildung grundsätzlich. Dennoch hat sich im deutschen Protestantismus eine Bildungsvorstellung durchsetzen können, die hin zum Kulturprotestantismus führte. Diese Entwicklung wurde aber nicht von Luther, sondern von Philipp Melanchthon in die Wege geleitet. Über Melanchthon hat auch das deutsche Reformiertentum sich seinen Eintritt in den deutschen Kulturprotestantismus zu verschaffen vermocht. Georg Bollenbeck hat auf die protestantischen Ursprünge des traditionellen deutschen Kultur- und Bildungsverständnisses hingewiesen und es von anderen Vorstellungen, namentlich im angelsächsischen Bereich und in Frankreich, abgegrenzt. ${ }^{44}$ Zwar habe in Deutschland das Bürgertum mit der Berufung auf Bildung den Leistungsgedanken gegen das Ständedenken des Adels gerichtet, aber damit gleichzeitig in Abwehr demokratischer Bestrebungen der unter ihm stehenden Klassen vom Staate gesicherte Karrieren beansprucht. Dadurch sei eine gesellschaftliche und ökonomische Ausrichtung der Bildung nicht in den Blick getreten.

„Auch die Führungsschichten aus ,Oxbridge` oder den Grandes Ecoles beziehen ihr Prestige aus dem Rang der Ausbildungsstätten, doch ihre Grammatik bleibt auf eine ,societas civilis bezogen, sie wertet mit ,civilisation' Politik und Wirtschaft nicht ab. Und ihre soziale Lage ist weniger isoliert und offener als die eines Bildungsbürgertums, das sich nicht nur vom traditionellen Stadtbürgertum und vom Adel abgrenzt, sondern das der Bourgeoisie schon mißtraut, ehe es sie eigentlich gibt." ${ }^{\text {45 }}$

Der Begriff der Bildung korrespondiert im Deutschen mit dem der Kultur, aber nicht mit dem des Gemeinwohls. Auf der anderen Seite wird nur dem Gebildeten ein Wissen um das Allgemeinwohl zugetraut, denn Bildung sei, so die klassische Definition Hegels, „Erhebung ins Allgemeine““ ${ }^{46}$

Von daher scheint man noch heute in Deutschland eher der Einzelpersönlichkeit denn Gruppen zu trauen, weil angenommen wird, daß in Parteien und Organisationen aller Art Partikularinteressen Ungebildeter sich leichter durchsetzen können, und man scheint entsprechend auch nur moralisch vorbildlichen und somit gebildeten Politikern zuzutrauen, Wege aus Krisen weisen zu können. Das Gewissen wird individualisiert gedacht, d. h. als Einspruchsinstanz nur der Einzelpersönlichkeit zugesprochen. Theologisch gesprochen wird damit das Gewissen zum Ort der Gottesbegegnungen. Die Möglichkeit, die das Luthertum eröffnet, daß der Einzelne für das Beharren im Glauben verantwortlich gemacht werden kann, erlaubte es bei entsprechendem Staatskirchentum einer Bildungselite, sich selbst zu reproduzieren, und in der Synthese von Humanismus und Reformation schuf sie sich ihre Ideologie in Gestalt des zu tradierenden Bildungsgutes. Die Prädestinationslehre kann hier nur als Angriff verstanden werden, und sie wird damit auch ohne weiteres richtig verstanden.

${ }^{44}$ Bollenbeck 1994.

${ }^{45}$ Ebd., S. 197.

${ }^{46}$ Hegel 1840, Propädeutik I § 41 ff. 
Die Reformatoren der Schweiz, namentlich Zwingli und Calvin, waren nun im Unterschied zu Luther selber Humanisten, und es mag auf den ersten Blick verblüffen, warum nicht gerade sie im Bildungsbereich eine Möglichkeit für einen syllogysmus practicus gesehen haben - daß also die Bildungsfähigkeit als Zeichen der Erwähltheit hätte gelten können, was die Prädestinationslehre abgeschwächt und den geplagten Gewissen hätte Entlastung gewähren können. Freilich sieht, wer so fragt, die Sache wieder aus einer Ecke, aus der heraus nicht verstanden werden kann, daß die Prädestinationslehre im Verständnis der Reformatoren ja gerade Entlastung der Gewissen ist. Man urteilt dann also wieder aus der liberalen Ecke heraus, wo man den Menschen primär als Einzelwesen sieht, der mit sich und der Welt in einer prästabilierten Harmonie existiert, die er, humanistisch gebildet, zu gestalten aufgerufen sei. So beurteilt Gottfried Locher Zwinglis Humanismus auch anders als jenen der Humanisten vom Schlage des Erasmus: „Zwinglis ,Humanismus“ war keine festumrissene Weltanschauung, sondern eine wissenschaftliche Haltung, eine philologische Methode und eine Wegstrecke innerer Entwicklung".47

Auch die Bildung wird sozialisiert. Sie dient weniger dem Einzelnen, sondern soll der Gemeinde dienen. Gewissen ist diesem Verständnis nach kein individuelles Vermögen, sondern immer ein soziales Phänomen. Insofern Erwählung Erwählung zum Dienst ist, ist Bildung dann Inanspruchnahme und Befähigung zum Dienst in der Gemeinde und damit Befähigung zur Freiheit. Sie ist auch nicht Dienst gegenüber einem Bildungsgut und einer Tradition, die an die folgende Generation weitergegeben und gepflegt werden müßten, worauf sich die Forderung nach Privilegien gewöhnlich zu berufen pflegt. Der Unterschied sei mit einem Beispiel aus Michael Walzers Sphären der Gerechtigkeit illustriert:

\begin{abstract}
"Ganz gewiß steht der Titel ,Doktor' all jenen Personen zu, die ihr Medizinstudium und die dazugehörigen Prüfungen absolviert und dabei eine bestimmte Note erreicht haben, wobei die Prüfungen jedoch nur darüber entscheiden, wer diese Personen sind und wie viele es von ihnen gibt. Mit anderen Worten, wenn jemand fleißig studiert, sich den vorgeschriebenen Stoff aneignet und sein Examen besteht, dann hat er es verdient, ein ,Doktor' zu sein. Es wäre ungerecht, ihm den Titel zu verweigern. Nicht ungerecht wäre es hingegen, ihm eine Assistenzarztstelle oder einen Amtsbereich an einem speziellen Krankenhaus zu versagen. Die Auswahlkommission des Krankenhauses muß nicht den Bewerber mit der besten Note auswählen; schließlich blickt sie nicht nur zurück auf seine Examina, sondern auch nach vorn auf noch nicht erbrachte, weil in der Zukunft liegende Leistungen. [...] Wenn Ämter mit all ihrer Autorität und ihren Vorrechten verdient werden könnten, dann wären wir der Gnade der Verdienstvollen ausgeliefert." ${ }^{\text {"48 }}$
\end{abstract}

Mit der Prädestinationslehre läßt sich damit nicht nur die Bildung von Dynastien, sondern auch die von Meritokratien nicht rechtfertigen, im Gegenteil. Ein weiterer Aspekt des reformierten Bildungsverständnisses, der auch als Folge der reformierten Rezeption des Humanismus verstanden werden kann und der die Vereinbarkeit des reformierten Selbstverständnisses mit einer Politik der Selbstrekrutierung von Bildungseliten ausschließt, besteht darin, daß es ihm nicht nur darum geht, den Menschen über den Bil-

${ }^{47}$ Locher 1979 , S. 80.

48 Walzer 1998, S. 207. 
dungsstoff auszubilden, sondern vielmehr auch darum, diesen Stoff selber erst zu bilden. Bildung heißt demnach nicht, über ein Bildungsgut zu verfügen, schon gar nicht über die Heilige Schrift. Die maßgeblich von Zwingli besorgte Übersetzung der Bibel bedarf der reformierten Tradition gemäß der ständigen Überarbeitung, was dazu geführt hat, daß in nahezu jedem Jahrhundert seit der Reformation eine Neuübersetzung der Zürcher Bibel vorgelegen hat. Derzeit ist eine Neuübersetzung in Arbeit. Die neue Übertragung der Psalmen und des Neuen Testaments liegt bereits vor. Bildung im reformierten Bereich ist also vorwiegend Sprachbildung, Hermeneutik im Dienste der Verkündigung. Bildung war hier von Anfang an pragmatisch ausgerichtet. Von daher wird in den angelsächsischen Ländern wohl auch heute noch Bildung mehr instrumental verstanden denn als Status. Sie hat sich im Alltag zu bewähren und nicht alleine in Prüfungen.

Was für die Bibel gilt, gilt analog auch für die Bekenntnisschriften des Reformiertentums: Es gibt kein zeitlos gültiges Bekenntnis, sondern das Bekenntnis muß immer wieder an der Schrift überprüft und dem Sprachgebrauch der Zeit entsprechend formuliert werden. Weil dabei zwischen zeitgemäßem Sprachgebrauch und Zeitgeist nicht unterschieden werden kann, bleibt der theologische Prozeß im Gang, der eben auch dem Dienst und damit der Freiheit der Gemeinde zu dienen hat. Das Luthertum dagegen betrachtet mit der Konkordienformel von 1577 und der Zusammenfassung der lutherischen Bekenntnisschriften im Konkordienbuch von 1580 die Bekenntnisentwicklung als abgeschlossen. Eine entsprechende Sammlung aller reformierten Bekenntnisse analog zu denen des Luthertums kann es aber nicht geben. Trotzdem hat es Jan Rohls unternommen, in seinem verdienstvollen Buch Theologie reformierter Bekenntnisschriften deren gemeinsamen theologischen Nenner herauszuarbeiten, ${ }^{49}$ wobei er allerdings nicht analytisch vorgeht, um ein reformiertes Prinzip zu ermitteln, sondern die Bekenntnisschriften als Kompendien unterschiedlichster Lehrmeinungen wertet. Rohls bestreitet insbesondere, daß die Prädestinationslehre ein solches reformiertes Prinzip sei. Unbestritten des Pluralismus, der in der reformierten Tradition sich zeigt, darf aber nicht vergessen werden, daß dieser Pluralismus nicht Selbstzweck ist, sondern sich dem fortwährenden Bemühen um den rechten Dienst der Gemeinde verdankt - und damit gerade dem Prinzip, das Rohls so ablehnt. Wenn also von einem reformierten Gemeinwohlverständnis die Rede sein soll, dann in dem Sinne, daß das Reformiertentum dafür eintritt, gesellschaftliche Verhältnisse so zu gestalten, daß die Herrschaft einer Elite und eines damit zusammenhängenden Gemeinwohlverständnisses erst gar nicht aufkommt. Diese Anliegen prägt das reformierte Verständnis von Demokratie maßgeblich.

\section{Demokratie}

Von Anbeginn an war die Bildung in den reformierten Gemeinden demokratisiert. Das betraf zunächst freilich die theologische Bildung, die aber seinerzeit die entscheidende war. Das Stift in Zürich wurde 1525 in die Prophezey umgewandelt und diente der Theologenausbildung. Die fand in enger Verbindung mit der Gemeinde statt. Jeden Wochen-

\footnotetext{
${ }^{49}$ Rohls 1987.
} 
tag, außer Freitags (wegen des Marktes), fanden sich alle Pfarrer, Prädikanten, Chorherren und die älteren Schüler des Stifts im Chor des Großmünsters ein, wo ein Bibeltext zunächst aus der Vulgata, dann aus der Hebräischen Bibel, dann aus der Septuaginta und schließlich auf deutsch vorgelesen und erläutert wurde. Dies geschah in Anwesenheit der Gemeinde. Fragen waren nicht nur gestattet, sondern ausdrücklich erwünscht. Die theologische Bildung der Gemeinde war nicht zuletzt im Hinblick auf die Gefährdung der Gemeinde und mit ihr der gesamten Reformation notwendig. In seinem jüngst erschienenen zweiten Teilband des zweiten Bandes seiner Dogmengeschichte schreibt Karlmann Beyschlag, der an gleicher Stelle allerdings auch glaubt, darauf aufmerksam machen zu müssen, daß von Genf aus eine Spur des Grauens durch die Jahrhunderte führe das gehört wohl zur zeitgemäßen anticalvinistischen Rethorik dazu: ${ }^{50}$

„Daß das deutsche Luthertum von der Gegenreformation nicht einfach überrollt wurde, verdankt es nicht zuletzt jenem todesmutigen Calvinismus, der sich wie ein westeuropäischer Schutzschild vor die mitteleuropäischen Verhältnisse legte und in den staatlichen Christenverfolgungen bis ins 18 . Jh. bis aufs Blut widerstanden hat. ${ }^{\text {"51 }}$

Die calvinistischen Gemeinden waren Gemeinden in der Anfechtung, für die die allgemeine Bildung eine Überlebensfrage insofern war, als damit durch die Wegsperrung einer wie auch immer gearteten Bildungsschicht die Gemeinden nicht in Existenznot hätten geraten können. Jedes Gemeindeglied sollte in der Lage sein, die Stelle des Predigers zu ersetzen. Dies gilt freilich auch für die anderen Aufgaben in der Gemeinde. Im Jahre 1559 erfolgte die Gründung der Genfer Akademie, und Calvin schrieb den Gemeinden in Frankreich: ,Schickt uns Holz und wir machen Pfeile daraus, die wir Euch zurückgeben". ${ }^{52}$ Die Ausrichtung der Bildung auf den Dienst in der Gemeinde reicht aber als Erklärung für den demokratischen Charakter der Gemeindeordnung reformierter Gemeinden nicht aus. Weitere Aspekte sind von noch entscheidenderer Bedeutung.

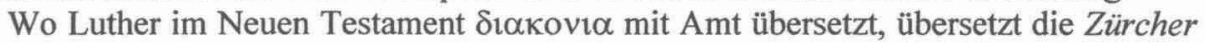
Bibel Dienst. Die Vorstellung, daß die Würdelosigkeit eines Amtsträgers der Würde des Amtes selber keinen Abbruch tue, läßt sich auf die Ausübung eines Dienstes nicht so ohne weiteres übertragen. Das Amt ist ein Status, der Dienst eine Aufgabe, die erfüllt wird oder nicht. Das Amt, weil es auch repräsentiert, hat ein Sein unabhängig von der Funktion, die erfüllt werden soll, der Dienst aber hat sein Sein nur im Geschehen des Dienens. Weil zum Dienst der Gemeinde alle, die ihr angehören, gleichermaßen berufen sind, muß die Organisation der Gemeinde grundsätzlich demokratisch sein. In Christus gibt es, um es mit Paulus zu sagen, weder Mann noch Frau, weder Freier noch Sklave, weder Jude noch Heide (Gal 3, 28). Diese Demokratie gründet darum in dem oben geschilderten Gemeindeverständnis und Menschenbild und damit in der Lehre von der Prädestination, sogar der Lehre von der doppelten Prädestination, weil sie, die Demokratie, maßgeblich der Machtkontrolle dient. Sie gründet nicht auf dem Prinzip einer Souveränität der Gemeinde, die sie sich selber verdankte, sondern der Souveränität Gottes, die sich wiederum in der Souveränität der Gemeinde gegenüber der Welt, ge-

\footnotetext{
${ }^{50}$ Beyschlag 2000, S. 411.

${ }^{51}$ Ebd., S. 415.

52 Zit. n. Smidt 1972, S. 107.
} 
genüber den Ansprüchen der Mächte und Gewalten, widerspiegelt. Solches Demokratieverständnis wurzelt nicht im Verfassungsdenken der Römer, sondern in dem des antiken östlichen Mittelmeerraumes. Die Begriffe, mit denen das Neue Testament die Gemeinde beschreibt, sind tatsächlich politischer Herkunft, so z. B. der schon erwähnte Begriff der $\lambda \varepsilon \imath \tau o u p \gamma \imath \alpha$, aber auch der Begriff der $\varepsilon \kappa \kappa \lambda \eta \sigma \iota \alpha$, der die Volksversammlung der $\pi \mathrm{o} \lambda \iota_{\varsigma} \varsigma$ meinte. Aber die Demokratie in der christlichen Gemeinde ist kein Selbstzweck.

Die Demokratie ist nicht das Leben der Gemeinde, aber sie ist die Art und Weise, wie die Gemeinde ihr Leben lebt. Weil ihr Leben der Christus ist, ist die Organisation der Gemeinde Christusbekenntnis. Im Bekenntnis bekennt die Gemeinde entsprechend auch ihre Verfassung. Ihr Leben aber ist ausgerichtet am Gesetz im Sinne des schon angesprochenen tertius usus legis. Das Gesetz ist, wie ausgeführt, die Ordnung der Freiheit und begründet entsprechend die Demokratie der Gemeinde. Das Gesetz besiegelt den Bund Gottes mit seinem Volk.

In seinem Essay Exodus und Revolution hat Michael Walzer einen Widerspruch zwischen dem Bundes- und dem Prädestinationsgedanken auszumachen geglaubt. ${ }^{53}$ Das Volk sei von Gott aus Ägypten befreit worden und dann während der Wüstenwanderung bis zum Bundesschluß am Berge Horeb in einem Zustand der Freiheit belassen worden - das entspricht übrigens dem Rechtfertigungsverständnis des Konkordienbuches. Dort, in der Wüste, habe es aber in einem freien Entschluß den Bund bejaht: „Da antwortete alles Volk wie aus einem Munde: Alle Worte, die der Herr gesagt hat, wollen wir tun" (Ex 24, 3). Walzer interpretiert das in Übereinstimmung mit einer ganzen Reihe von Rabbinen so, daß jeder Einzelne den Bund mit Gott geschlossen habe, was dem Prädestinationsgedanken widerspräche. Es gibt aber noch ein weiteres Verständnis, das Walzer auch erwähnt, und das den Texthinweis besonders ernstnimmt, daß das Volk ,wie aus einem Munde" geantwortet habe. Hier kann das Volk nicht im Sinne der Summe aller Einzelnen verstanden werden, Volk meint etwas anderes als Bevölkerung. Reformiertem Verständnis gemäß spricht hier der Geist, der eben ein soziales und kein individuelles Phänomen ist, insbesondere der Heilige Geist, der schon vor dem Hintergrund der Trinitätslehre nicht individualistisch gedacht werden kann. Ex 24,3 scheint mir daher eher eine Akklamation zu sein mit propagandistischer Funktion und mit verpflichtendem Charakter.

Aber das Gesetz, wie es in der Bibel überliefert ist, ist nicht alleine Gegenstand der Bildung, den die Lehrer und Prediger nur zu vermitteln hätten, es muß selber immer wieder übersetzt und damit neu verstanden werden. Das Leben der Gemeinde ist darum auch Interpretationsgemeinschaft. Wie das $\mathrm{zu}$ verstehen ist, illustriert eine Geschichte aus dem Talmud, die Michael Walzer in seinem Buch Interpretation and Social Criticism erzählt: Einige Rabbinen diskutieren darüber, wie eine Stelle des Gesetzes zu verstehen sei. Rabbi Eliezer hat alle Argumente für seine Auffassung vorgetragen, aber ohne Erfolg, denn die anderen verweigern ihre Zustimmung. Ein Johannesbrotbaum möge sich vom Boden in die Luft erheben, wenn das Gesetz so verstanden werden müsse, wie er es ausgeführt habe, fordert Rabbi Eliezer, und der Baum erhebt sich tatsächlich in die Luft. Rabbi Josuah aber erklärt, ein Baum habe keine Autorität über das Ver-

53 Walzer 1988, S. $89 \mathrm{ff}$. 
ständnis des Gesetzes. Ein Fluß möge den Berg hinauffließen, wenn seine, Rabbi Eliezers Auffassung, zutreffe. Das Ereignis, das prompt eintritt, wird von Rabbi Josuah dahingehend kommentiert, daß ein Fluß nicht über das Gesetz entscheiden könne. Die Mauern des Lehrhauses mögen in sich zusammenfallen, wenn er Recht habe, so Rabbi Eliezer, was die Mauern auch tun; aber Rabbi Josuah erwidert ungerührt, daß Mauern das Gesetz nicht auszulegen hätten. Schließlich bittet Rabbi Eliezer den Himmel um ein endgültiges Urteil. Eine Stimme erschallt von oben und sagt: „,Warum widersprecht ihr Rabbi Eliezer? Er hat in allen Punkten recht“. Da sagt Rabbi Josuah: „Das Gesetz ist nicht im Himmel“. ${ }^{54}$

\section{Demokratie und Sozialkritik}

In der reformierten Gemeindeordnung sind alle Stränge reformierter Frömmigkeit miteinander verknüpft. Sie ist also nicht zufällig. Sie ist in ihrer Ausrichtung auf das Gesetz aber nicht nur demokratisch, sondern auch sozialkritisch, oder anders gesagt, gerade in ihrer besonderen Art der Sozialkritik demokratisch. Das bestimmt ihr Verhältnis zum politischen Umfeld und kennzeichnet das reformierte Gemeinwohlverständnis dann nicht mehr nur im Formalen, sondern auch inhaltlich. Walzer hat drei Wege der Sozialkritik voneinander unterschieden: Sozialkritik beruhe entweder auf Entdeckung, auf Erfindung oder auf Interpretation. Entdeckung und Erfindung setzten einen oder mehrere geniale, von der Gemeinschaft zumindest zeitweise abgesonderte Führer voraus, die ihre Entdeckung aber, so Walzer, nur scheinbar unabhängig von der herrschenden Moral machten:

„the moralities we discover and invent always turn out, and always will turn out, remarkably similar to the morality we already have. Philosophical discovery and invention (leaving aside divine revelation) are disguised interpretations; there is really only one path in moral philosophy“. ${ }^{\text {. } 5}$

Auch wenn Walzer einschränkend anerkennt, daß z. B. der Utilitarismus durchaus eine Erfindung genannt zu werden verdiene, so betrachtet er den Weg der Interpretation als den alleine sinnvoll gangbaren Weg und illustriert ihn am Beispiel des biblischen Propheten Amos. Unschwer kann man in Walzers Konzept den Widerwillen gegen sich selbst rekrutierende und sich gegenüber dem gesellschaftlichen Alltag und seine Herausforderungen abschottende Eliten wiedererkennen. Demokratische Sozialkritik reflektiere immer auf schon anerkannte moralische Gebote und Gesetze, wie eben die alttestamentliche Prophetie: „The first thing to notice is that the prophetic message depends upon previous messages. ${ }^{\text {“56 }}$ Als Gegenbeispiel zu Amos führt Walzer den Propheten Jonas an, der bekanntlich zu den Heiden in die Stadt Ninive geschickt wurde und, in

54 Walzer 1993, S. 31 f. Die deutsche Übersetzung von ,Interpretation and Social Critcism“ hat den Titel mit „Kritik und Gemeinsinn. Drei Wege der Gesellschaftskritik“" (Berlin 1990) nicht korrekt wiedergegeben.

55 Ebd., S. 21.

56 Ebd., S. 71. 
Unkenntnis ihres Moralkodexes, dort nichts anderes als den Untergang vorauszusagen wußte - er hatte buchstäblich nichts zu interpretieren. Statt des Untergangs hätte er wahlweise auch eine Utopie predigen können. Prophetische Kritik ist demnach das, was, um es kurz zu sagen, Karl Marx einmal in die Worte faßte: Man muß die versteinerten Verhältnisse zum Tanzen bringen, indem man ihnen ihre eigene Melodie vorspielt. ${ }^{57}$ Um im Bild zu bleiben: Die Demokratie ist der Tanzboden, auf dem dann zum Tanz aufgespielt wird. $\mathrm{Zu}$ was wäre aber ein Tanzboden nütze, würde darauf nicht getanzt? Die Tanzkapelle wäre in einer Gesellschaft, deren Eliten sich noch dem Christentum als verpflichtet behaupten - alleine die Behauptung genügt, ob sie es tatsächlich sind oder nicht, ist in diesem Zusammenhang uninteressant - die reformierte Gemeinde, und die Melodie, man ahnt es schon, wäre nichts anderes als die Lehre von der doppelten Prädestination.

Der Calvinismus stellt, wenn man so will, den Kältestrom innerhalb der Kirchengeschichte dar. Die Lehre von der Prädestination macht frösteln, in der Tat - aber doch nur jene, die im Warmen sitzen. Sie revolutioniert die Gesellschaft permanent, sofern eine Gesellschaft sich als eine christliche Gesellschaft versteht. Über dieses Verständnis entscheidet aber nicht dies abstrakte Gebilde Gesellschaft, sondern jene Elite, die das öffentliche Bild der Gesellschaft prägt. Sie gilt es beim Wort zu nehmen. Es gilt m. a. W., Interpretationsmonopole aufzubrechen. Die Reformierten könnten dann ähnlich beurteilt werden, wie laut Thukydides schon die Korinther die Athener charakterisiert haben: „Wenn daher jemand zusammenfassend behauptete, sie seien dazu geschaffen, weder selbst Ruhe zu halten noch die anderen Menschen in Ruhe zu lassen, so hätte er vollkommen recht. ${ }^{\text {"S8 }}$ Genf war nicht Rom, auch nicht Jerusalem, sondern Athen in einem Sinne, wie es sich die Humanisten nicht haben träumen lassen. Damit aber wären die schweizer Reformatoren gerade die eigentlichen Renaissancehumanisten gewesen, und nicht Erasmus, aber auch nicht Melanchthon. Doch das steht auf einem anderen Blatt.

Gemeinwohl ist ein offenzuhaltender Begriff. Das ist die Essenz des reformierten Gemeinwohlverständnisses. Darum ist das Gemeinwohl dieser Tradition gemäß gleichzusetzen mit allgemeiner Bildung und Demokratie. Beide ermöglichen eine Sozialkritik, die der Erhaltung der Demokratie und dem freien Zugang zur Bildung dient. Diese hat wiederum demokratieerhaltende Funktion. In der Prädestinationslehre findet diese Ordnung ihre Rechtfertigung. Und so sei Shakespeare, mit dem die vorliegenden Überlegungen schon eingeleitet worden sind, auch das letzte Wort gelassen, wenn ich abschließend Calvin über die Jahrhunderte hinweg zurufe - und manch einer mag da noch jemand anderen in diesen Ruf mit einstimmen hören: „Brav gewühlt, alter Maulwurf! ‘ 59

\footnotetext{
57 Marx 1981, S. 381.

58 Thukydides, Der Peloponnesische Krieg, 1,70.

59 Shakespeare, Hamlet, 1,5; siehe auch Marx 1974, S. 115.
} 


\section{Literaturverzeichnis}

Die Bekenntnisschriften der evangelisch-lutherischen Kirche. Hrsg. im Gedenkjahr der Augsburgischen Konfession 1930. Göttingen 1959.

Beyschlag, K. (2000), Grundriß der Dogmengeschichte Bd. II, Gott und Mensch, Teil 2, Die abendländische Epoche, Darmstadt.

Bollenbeck, G. $\left(1994^{2}\right)$, Bildung und Kultur. Glanz und Elend eines deutschen Deutungsmusters.

Calvin, J. (1988a), Unterricht in der christlichen Religion (Institutio christianae Religionis), Übers. von Otto Weber. Neukirchen-Vluyn.

Calvin, J. (1988b), Von der ewigen Vorherbestimmung Gottes (De aeterna Dei praedestinatione). Lat.deutsch, übers. von Wilhelm H. Neuser, Düsseldorf.

Cottret, B. (1988), Calvin, Paris.

Elert, W. (1953), Morphologie des Luthertums, München, Bd. 2.

Hegel, G. W. F. (1840), Philosophische Propädeutik, hg. von Franz Rosenzweig, 1840.

Hofmann, H. (2000), Einführung in die Rechts- und Staatsphilosophie, Darmstadt.

Jacobs, P. (1937), Prädestinationslehre und Verantwortlichkeit, Neukirchen.

Köberle, A. (1929), Rechtfertigung und Heiligung. Eine biblische, theologiegeschichtliche und systematische Untersuchung, Leipzig.

Locher, G. (1979), Die zwinglianische Reformation im Rahmen der europäischen Kirchengeschichte, Göttingen und Zürich.

Marx, K. (1974), Der achtzehnte Brumaire des Louis Bonaparte, Berlin.

Marx, K. (1981), Kritik der Hegelschen Rechtsphilosophie. Einleitung, in: MEW Bd.1, Berlin.

Moltmann, J. (1961), Prädestination und Perseveranz. Geschichte und Bedeutung der reformierten Lehre „de perseverantia sanctorum“, München.

Quervain, A. de (1953), Ethik II. Ehe und Haus, Zürich.

Rohls, J. (1987), Theologie reformierter Bekenntnisschriften, Göttingen.

Rohls, J. (1999), Zwischen Bildersturm und Kapitalismus. Der Beitrag des reformierten Protestantismus zur Kulturgeschichte Europas, Wuppertal.

Schöffler, H. (1960), Wirkungen der Reformation, Frankfurt/M.

Smidt, U. (Hg., 1972), Johannes Calvin und die Kirche, Stuttgart.

Smith, A. (1776), An Inquiry into the Nature and Causes of the Wealth of Nations, London.

Thukydides (1991), Der Peloponnesische Krieg, Übers. Von G. P. Landmann, München.

Wallace, D. D. (1982), Puritans and Predestination. Grace in English Protestant Theology, The University of North Carolina Press.

Walzer, M. (1993), Interpretation and Social Criticism, Harvard.

Walzer, M. (1988), Exodus und Revolution, Berlin.

Walzer, M. (1998), Sphären der Gerechtigkeit. Ein Plädoyer für Pluralität und Gleichheit, Frankfurt/M.

Weber, M. (1988), Die protestantische Ethik und der Geist des Kapitalismus, in: Gesammelte Aufsätze zur Religionssoziologie, Tübingen. 